American Journal of Surgical Research and Reviews
(ISSN:2637-5087)

\title{
Blue Round Small Cell tumor: A Surgical Update of DSRCT with review of literature 'A Grim Affair'
}

\author{
Dr.UwaisRiazUlHasan ${ }^{3}$ M.Med, Dr.Khathija Hasan M.Med, Dr.Farooq Ahmed Qureshi MS, \\ Dr. Victor Effiong Obong M.B.B.Ch, MWACS, Dr.Abdul Aziz Al Nami M.B.B.S, Dr.Ali Ibrahim \\ AIShaqaqiq M.B.B.S, Dr.Mohammad AbdulMajeed Alghadeer M.B.B.S Dr. Marwan Ahmad \\ AlRayhan M.B.B.S, Dr. Mohammed Ali AlJummah M.B.B.S, Dr.Baqer Ali Aldheen M.B.B.S, \\ Dr. Ali Hussain AIRufayi MD, Dr.ShehlaRiazUIHasan Phd. \\ Dr. Moath AbdulAziz AIMasoud² M.D, Dr. Noura Al Dossary ${ }^{1}$
}

Department of General Surgery, Al Omran General Hospital, Al Hassa, Kingdom of Saudi Arabia. Hospital Director ${ }^{1}$, Head of department ${ }^{2}$, Assoc Consultant General Surgeon ${ }^{3}$

\section{ABSTRACT}

Desmoplastic small round cell tumor (DSRCT) is a tumor derived How to cite this article:

from the Greek desmos referring to knot and plasis to formation UwaisRiazUIHasan, Khathija an uncommon soft tissue malignant tumor, mesenchymal in ori- Hasan, Farooq Ahmed Qureshi, gin and aggressive with a prelidiction for males and advanced at Victor Effiong Obong, MWACS, Abpresentation. It was first described as a distinct clinical entity by dul Aziz Al Nami, Ali Ibrahim AIShGerald WL and Rosai J [7]. There are fewer than 200 reported aqaqiq, Mohammad AbdulMajeed to date. Depending on the primary site of location the Clinical Alghadeer, Marwan Ahmad AlRaymanifestations vary. As most arise from the abdomen and pelvis han, Mohammed Ali AlJummah, they remain asymptomatic till they attain a huge size. Other re- Baqer Ali Aldheen, Ali Hussain Alported sites are the skull, thorax, and paratesticular region [10,13]. Rufayi,ShehlaRiazUIHasan, Moath We report the case of a $19 \mathrm{yr}$ old male who had non specific ab- AbdulAziz AIMasoud, Noura AI dominal discomfort with asthenia for a period of six months and Dossary. Blue Round Small Cell tuwas referred to us for evaluation of left supraclavicular nodes. mor: A Surgical Update of DSRCT The prognosis of Desmoplastic small round cell tumor (DSRCT) with review of literature 'A Grim Afis poor with few surviving less than two years.

fair'. American Journal of Surgical

Keywords: Blue round, Desmoplastic small round cell tumor, Research and Reviews, 2021, 4:31. Radiology, Multimodal therapy.

${ }^{*}$ Correspondence to Author:

Dr.UwaisRiazUIHasan

Consultant General Surgeon, Department of General Surgery, Al Omran General Hospital, Al Hassa, Kingdom of Saudi Arabia. Assoc 


\section{Introduction}

Desmoplastic small round cell tumor [DSRCT] is a rare, aggressive, malignant tumor. The European Union, Surveillance of Rare Cancer in Europe [RARECARE] describe 'rare cancer' as those with fewer than 6 cases per 100,000. Desmoplastic small round cell tumor [DSRCT] predominantly affects young males with a male:female ratio of $4: 1^{[6]}$, most affected are in the second decade. The median age at diagnosis is approximately 21 years [9] with a survival reported as less than two years. The tumor is characterized by nests of small blue tumor cells surrounded by a cellular and vascular collagenous stroma with a desmoplastic reaction. Histogenitically the cell of origin is not clear most authors have stated it to be from primitive mesenchymal cells or tissue, still others believe it is neuro ectodermal in origin [3]. It is associated with a unique chromosomal translocation t [11:22] [p13; q 12] that involves the EWSR1 and WT1 genes ${ }^{[8]}$. The liver and lung are the common sites of secondary metastasis other extraperitoneal sites also have been described ${ }^{[1]}$. The survival is just over a year after diagnosis. The reason for this poor prognosis ${ }^{[6]}$ is a delay in diagnosis and partly as no standard therapy is available. The fact that it affects young patients, masquerading with vague abdominal pain, constipation, distension, ascites, weight loss, and jaundice [29] and advanced when diagnosed with no consencsus on treatment merits discussion on this topic.

\section{Case report}

A 19 year old Male who presented with a history of right loin pain and back pain and painless groin swelling followed by fixed left neck nodes for the past three months. This patient had a total of three presentations over three months in $\mathrm{A} / \mathrm{E}$ twice for back pain and finally for a painless left groin swelling that was followed by left neck swelling. It was then referred to General Surgery for biopsy of left side neck nodes.

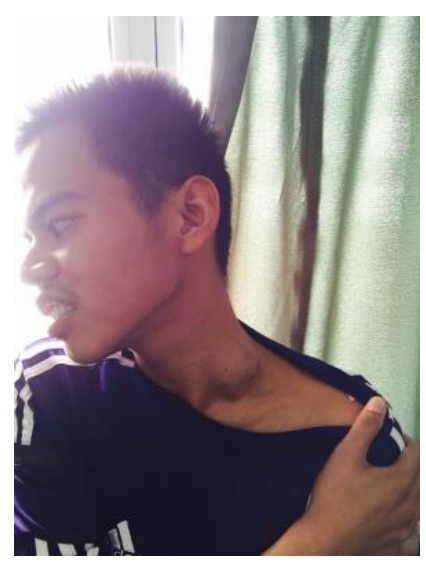

Fig.1

O/E Mr N was a thin $19 \mathrm{yr}$ old, Wt $56 \mathrm{~kg}$ Afebrile with a normal pulse respiratory rate and BP. He had hepatomegaly $4 \mathrm{~cm}$ below right costal margin. His initial investigations revealed a hemoglobin of $13.9 \mathrm{~g} / \mathrm{dL}$, leucocytosis [TLC = $12.3 \times 10$ 9/L] a hematocrit of 40, platelet count of $406 \times 109 / \mathrm{L}$, His ESR was $23 \mathrm{~mm}$ in the first hour by the Wintrobe's method. Serum LDH was $468 \mathrm{U} / \mathrm{L}$, An LFT bilirubin 11.3 micro/L, Albumin 40g/L, GGT 447, ALP 184, ALT 58. CT 37sec,
PT10sec, INR 0.8. The remaining biochemical parameters were essentially normal. An enzyme-linked immunosorbent assay [ELISA] for human immunodeficiency virus [HIV] was non-reactive. Urine REME was normal.

An abdomen USG of the showed an enlarged liver with multiple hypoechoic areas of variable sizes in both the lobes of the liver with minimal ascites. There were multiple hypoechoic lesions of variable size, with target appearance seen in 
the liver that were suspicious for metastasis. He underwent FNAC evaluation and an USG Few enlarged abdominal lymph nodes are seen. guided core of biopsy of the left supraclavicular The pancreas, spleen, and kidneys are nodes His right costal and right groin lymph were unremarkable. No splenomegaly. No also subjected for an open Excision Biopsy. His hydronephrosis. The right kidney measured 10 biopsy revealed presence of Round blue tumor $\mathrm{cm}$ and the left kidney measured $11 \mathrm{~cm}$, in bipolar length. No focal lesion seen in both testes. In the region of the right inguinal canal, a $1.9 \times 1.5 \mathrm{~cm}$ hypoechoic lesion is seen lymph node. The rest of the abdominal ultrasound was normal. cells surrounded by sheets of fibrous stroma. There was presence of mitosis and focal areas of necrosis. IHC revealed WT-1positive, Vimentin positive, LCA positive, Desmin positive, Myogenic positive, EMA positive, CD99 positive S100 negative.

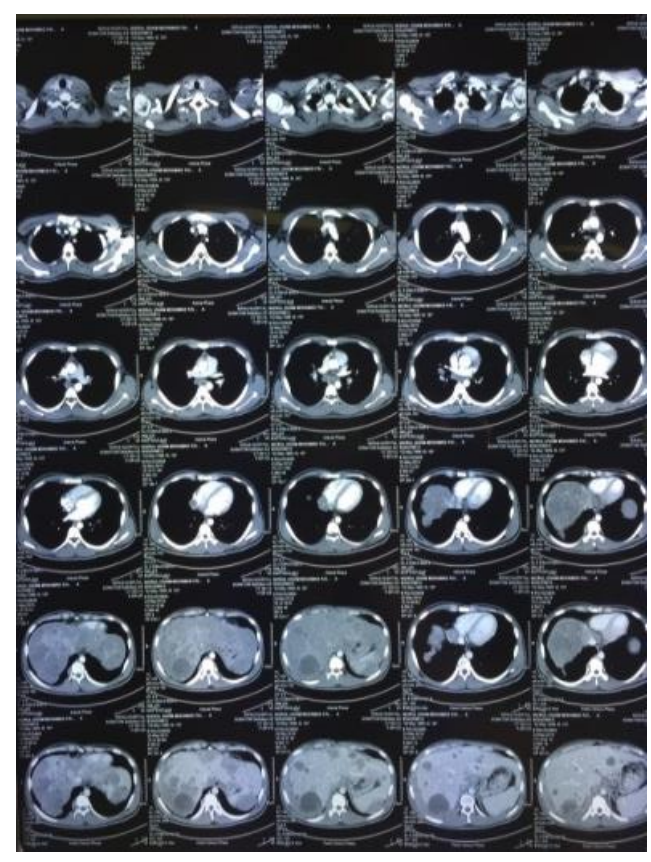

Fig.2

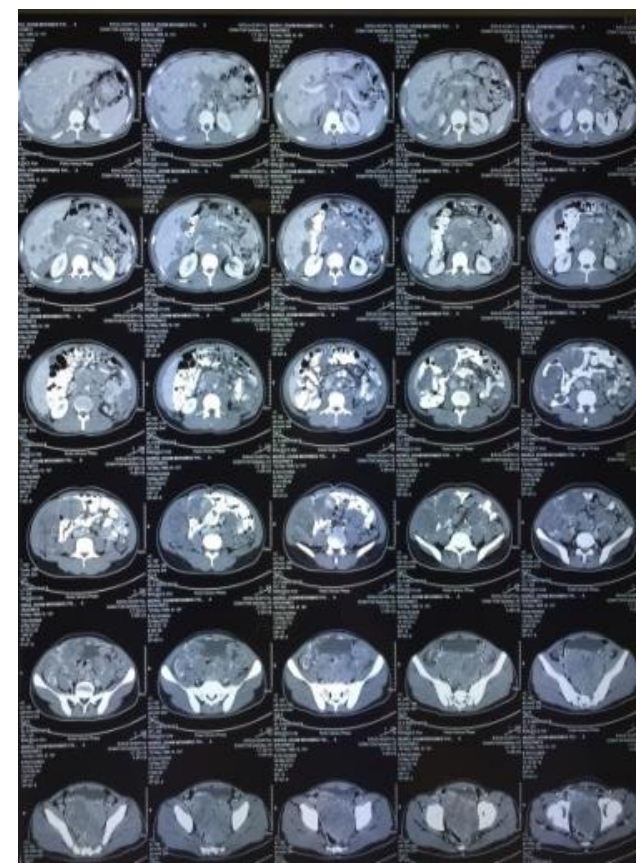

Fig.3 


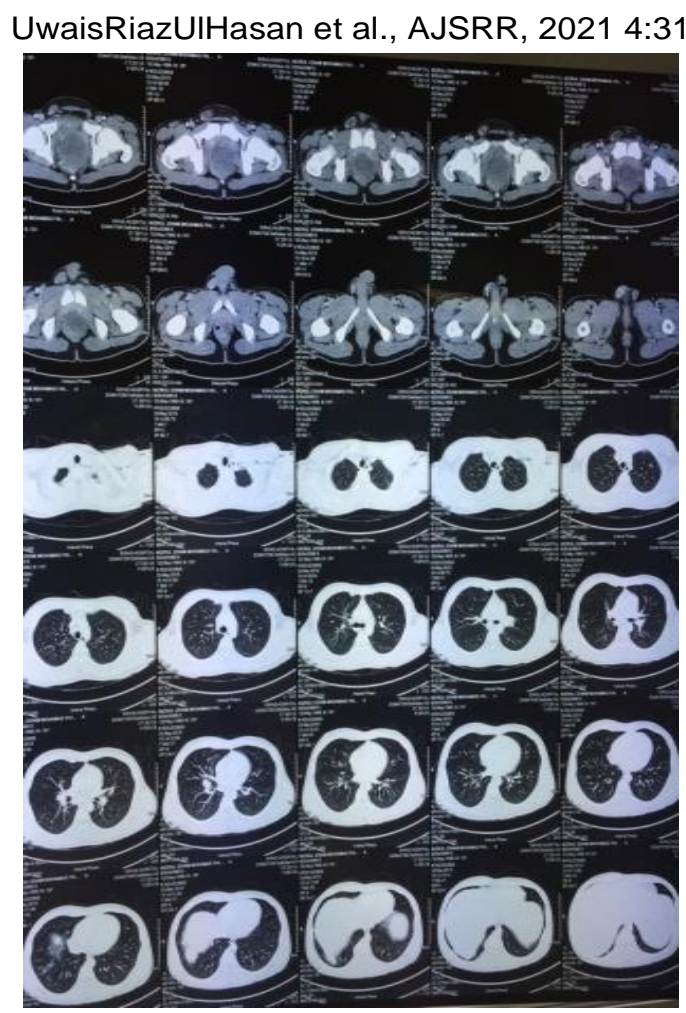

Fig.4

Staging CT TAP reported Bilateral supraclavicular lymphadenopathy, largest on the left, measuring about $3 \mathrm{~cm}$ short-axis diameter. Left axillary lymphadenopathy, measuring about 1.2 $\mathrm{cm}$. Several mediastinal lymphadeno-pathies. Subcarinal enlarged lymph nodes, Bilateral enlarged hilar lymph nodes, largest on the right. There was no pleural effusion. Multiple hypodense hepatic lesions of variable size, and multiple enlarged lymph nodes are seen in the abdomen and pelvis. Enlarged peritoneal nodes scalloping the hepatic outlines; and multiple significantly enlarged conglomerate lymph nodes throughout the abdomen, some with calcifcation, displacing the bowel are noted. Enlarged lymph nodes in the right groin noted. No splenomegaly. Kidneys, left adrenal and pancreas are unremarkable. Right adrenal is not well seen. L1 vertebra was Sclerotic.

He was diagnosed as having Advanced Stage IV metastatic Desmoplastic small round cell tumor [DSRCT] disease and was referred to our tertiary care centre for Palliative chemoradiotherapy. This young male eventually scummed to his illness within a year of his diagnosis.

Discussion
DSRCT is an uncommon aggressive, malignant tumor of the serosal surfaces of the peritoneum [18] arising along the abdominal surface, in the thoracic cavity along pleural lining or if extraabdominal particularly in the groin as para testicular growths $[19,20]$. It is not known if the tumor was primarily abdominal and then spread to the paratesticular region as tumor spill through the deep ring or if it started primarily in the paratesticular groin. The disease most commonly presents with a multinodular growth on the serosal surfaces whether in the abdominal or thoracic cavity.

The DSRCT is an aggressive tumor with a desmoplastic reaction so called as nests of blue small tumor cells are surrounded by a cellular collagenous stroma ${ }^{[15]}$. The tumors form a pure cellular growth without production of tumor matrix. The common denominator is an undifferentiated, small round basophilic [bluish], with scant cytoplasm, poor stroma, highly cellular tumor. They are described as blue coloured nests of small active tumor cells proliferating in a stroma. Desmoplastic small round cell tumor [DSRCT] is of blastomatous cell of origin. Typically on immune histochemical 
analysis they are positivity for desmin, vimentin keratin and Neuron specific enolase [NSE].The presence of perinuclear dot-like immunostaining with desmin strongly suggests a diagnosis of DSRCT ${ }^{[21] .}$

These Blue round tumors or DSRCT have a unique translocation of chromosomes $t[11 ; 22]$ [p13; q12] [25,26]. The growth of this tumor is the result of this unique chromosomal arrangement [27]. The EWS-WT1 brings about up regulation of the several genes [27], and several growth factor genes like MYC, PAX2,PDGFRA, WT1, IL15 IGF1R, EGFR, IL2, [28]. PDGFRa induces neoangiogenesis and proliferation of fibroblasts $[29,8]$. Molecular studies along with PCR, FISH, immunohistochemistry staining of epithelial, mesenchymal and neural antigens within the same cell [3], greatly aids in the diagnosis of these tumors and karyotyping analysis are thus diagnostic of DSRCT.

Most common site reported is the abdomen if the tumor is primarily in the thorax it manifests with chest pain and shortness of breath with pleural effusion [13] [16]. Other sites of Desmoplastic small round cell tumor [DSRCT] disease include uterine and ovarian serosal surface, skull, even the parotid region [10,13,14,12]. An important differential diagnosis includes primitive neuroectodermal tumor [PNET], Ewing's sarcoma, small cell mesothelioma, malignant non-Hodgkin's lymphoma, Neuroblastoma, rhabdomyosarcoma and [15], [24]. A useful clinical marker in the management is the serum LDH level [22], serum CA125 is another marker whose levels are elevated ${ }^{[22]}$. The common radiological feature on the CT scan is the presence of multiple abdominal masses that are synchronous with no obvious solid or hollow organ origin [20]. Other features include a dominant heterogenous mass in the retrouterine and retrovesical space, the result of peritoneal pooling ${ }^{[17]}$. MRI can be helpful in delineating the extent of the disease, if surgical resection is considered ${ }^{[30]}$. The presence of ascites affects survival, as it may be the only indication of liver metastasis.
Treatment is Multimodal Surgical, Chemotherapy and Radiotherapy ${ }^{[2]}$. Surgical resection is sited as predictor of prolonged overall survival $[11,4]$. Several have advocated the use of hyperthermic intraperitoneal chemotherapy [HIPEC] following debulking of the abdominal tumor [90\% resection] in patients with DSRCT [32]. Metastasis is by lymph nodes to liver and lungs survival rates at 3 years of less than 30\% [5] are reported. The median overall survival of two years for those with non metastatic abdominal tumors who underwent debulking surgery ${ }^{[15]}$, The Median overall survival after surgery is significantly longer than those without surgery ${ }^{[32]}$. What is important to note is the side effects of chemotherapy like rebleeding requiring reexploration and nephrotoxicity that adds to the morbidity and to achieve a long term disease free state of even one year is marred by remissions. Bone marrow ablation, and immunotherapy with chemotherapy are currently novel treatment approaches [23]. Cancer vaccines seek to induce tumor immune responses through antigen presentation and stimulation of new $T$ cell responses ${ }^{[31]}$, but the current evidence does not support their use. With aggressive Multimodal therapy and complications of chemotherapy and radiation the outlook for patients with Desmoplastic small round cell tumor [DSRCT] disease continues to be bleek. Early diagnosis improves outcome only temporarily.

\section{Conclusion}

DSRCT is an aggressive tumor, with disease familiarity currently restricted to case reports. A high index suspicion is required especially in young patients who are juggled between treating family care physicians, before referral to tertiary care centres for managment. The fact that the symptoms of the disease process in DSRCT are subtle and non specific there is inevitably a delay in diagnosis As of today there are given no universal accepted standard of treatment, the Multimodal approach Surgical debulking and hyperthermic intraperitoneal chemotherapy [HIPEC] are the current modalities but having 
said that the overall survival despite aggressive continues to be poor as complete disease remission is seldom achieved. More research studies and a better understanding of the genetics and molecular mechanisms may pave the way for standardisation of protocols. Until then outcomes for those affected continues to be a grim affair.

Declaration of Consent: Appropriate patient consent forms were obtained.

Conflict of Interest: Non.

\section{Acknowledgement}

The author would personally like to thank $\mathrm{Dr}$ Khathija Hasan for her contribution to the article.

\section{References}

[1]. A. Hayes-Jordan and P. M. Anderson, "The diagnosis and management of desmoplastic small round cell tumor: a review," Current Opinion in Oncology, vol. 23, no. 4, pp. 385389, 2011.

[2]. B. H. Kushner, M. P. LaQuaglia, N. Wollner et al. "Desmoplastic small round-cell tumor: prolonged progression-free survival with aggressive multimodality therapy," Journal of Clinical Oncology, vol. 14, no. 5, pp.15261531,1996.

[3]. Chang F. Desmoplastic Small Round Cell Tumors: Cytologic, Histologic,and immunohistochemical Features. Arch Pathol Lab Med. 2006;130:728-732.

[4]. D. R. Lal, W. T. Su, S. L. Wolden, K. C. Loh, S. Modak, and M. P. La Quaglia, "Results of multimodal treatment for desmoplastic small round cell tumors," Journal of Pediatric Surgery, vol. 40, no. 1, pp. 251-255, 2005.

[5]. Dufresne A, Cassier P, Couraud L, et al. Desmoplastic Small Round Cell Tumor: Current Management and Recent Findings. Clin Sarcoma Res.2013;3:14.

[6]. Gerald WL, Ladanyi M, De Alava E, et al. Clinical, pathologic and molecular spectrum of tumors associated with $t[11 ; 22][p 13 ; q 12]$ : desmoplastic small round-cell tumor and its variants. J Clin Oncol. 1998;16[9]:3028-3036.

[7]. Gerald WL, Miller HK, Battifora H, Miettinen M, Silva EG, Rosai J. Intraabdominal desmoplastic small round-cell tumor: report of 19 cases of a distinctive type of high-grade polyphenotypic malignancy affecting young individuals. $A m \mathrm{~J}$ Surg Pathol. 1991;15:499-513W.L.
[8]. J. Liu, M. M. Nau, J. C. Yeh, C. J. Allegra, E. Chu, et al "Molecular heterogeneity and function of EWS-WT1fusion transcripts in desmoplastic small round cell tumors"

[9]. Kretschmar CS, Colbach C, Bhan I, Crombleholme TM. et al Desmoplastic small cell tumor: A report of three cases and a review of the literature. J Pediatr Hematol Oncol. 1996;18:293-8.

[10]. O.W. Cummings, T.M. Ulbright, R.H. Young, A.P. Dei Tos, et al. Desmoplastic small round cell tumors of the paratesticular region. A report of six cases, Am. J. Surg. Pathol. 21 [1997] $219 \mathrm{e} 225$.

[11]. R. E. Schwarz, W. L. Gerald, B. H. Kushner, D. G. Coit, et al M. F. Brennan, "Desmoplastic small round cell tumors: prognostic indicators and results of surgical management," Annals of Surgical Oncology, vol. 5, no. 5, pp,416-422, 1998.

[12]. Tison V, Cerasoli S, Morigi F, et al Intracranial desmoplastic small-cell tumor: report of a case. Am J Surg Pathol. 1996;20:112-117.

[13]. V. Parkash, W.L. Gerald, A. Parma, M. Miettinen, et al, Desmoplastic small round cell tumor of the pleura, Am. J. Surg. Pathol. 19 [1995].

[14]. Xiang L, Jing $Y$, Shibao F, Xiaoming $X$, Jie Z. et al, Desmoplastic small round cell tumor: a case report and review of the literature. World Journal of Surgical Oncology. 2014;12:9.

[15]. Wong $\mathrm{HH}$, Hatcher $\mathrm{HM}$, Benson $\mathrm{C}$, et al. Desmoplastic small round cell tumour: characteristics and prognostic factors of 41 patients and review of the literature. Clin Sarcoma Res. 2013;3[1]:14.

[16]. Z.M. Wang, W.B. Xiao, S.S. Zheng, et al. Desmoplastic small round cell tumor of the lung: case report, Chin. Med. J. Engl. 120 [2007] $2327 \mathrm{e} 2328$.

[17]. Richard Bellah, Lisa Suzuki Bordalo, Eric Brecher et al.Desmoplastic small round cell tumors in the abdomen and pelvis: A report of the $C T$ findings in Eleven Children and Young Adults. Am Journal of Roentgenology. 2005;184:1910-1914. 10.2214/ajr.184.6.01841910.

[18]. Choi JK, van Hoeven K, Brooks JJ, et al. Desmoplastic small round cell tumor presenting in pleural fluid and accompanied by desminpositive mesothelial cells. Acta Cytol. 1995;39:377-378.

[19]. Roganovich J, Bisogno G, Cecchetto G, et al. Paratesticular desmoplastic small round cell tumor: case report and review of the literature. $J$ Surg Oncol. 1999;71:269-272. 
[20]. Takhtani D, Saleeb SF, Teplick SK et al. General case of the day. Desmoplastic small roundcelltumorof the abdomen with scrotal metastases. Radiographics. 1999;19:252-254.

[21]. Ordóñez NG. Desmoplastic small round cell tumor: I: a histopathologic study of 39 cases with emphasis on unusual histological patterns. $A m \mathrm{~J}$ Surg Pathol. 1998;22:1303-1313.

[22]. Yoshizawa J, Maie M, Eto $T$, et al. A case of intra-abdominal desmoplastic small-round-cell tumor with elevated serum CA125. Pediatr Surg Int. 2002;18:238-240.

[23]. Mazuryk M, Paterson AH, Temple $W$, et al. Benefit of aggressive multimodality therapy with autologous stem cell support for intra-abdominal desmoplastic small round cell tumor. Bone Marrow Transplant. 1998;21:961-963.

[24]. Thway K., Noujaim J., Zaidi S., et al. Desmoplastic Small Round Cell Tumor: Pathology, Genetics, and Potential Therapeutic Strategies. Int. J. Surg. Pathol. 2016;24:672684. doi: 10.1177/1066896916668637.

[25]. Sawyer J.R., Tryka A.F., Lewis J.M. et al. A Novel Reciprocal Chromosome Translocation t[11;22][p13;q12] in an Intraabdominal Desmoplastic Small Round-Cell Tumor. Am. J. Surg. Pathol. 1992;16:411-416. doi: 10.1097/00000478-199204000-00010.

[26]. Rodriguez E., Sreekantaiah C., Gerald W. et al., A Recurring Translocation, t[11;22][p13;q11.2], Characterizes Intra-Abdominal Desmoplastic Small Round-Cell Tumors. Cancer Genet Cytogent. 1993;21:17-21. doi: 10.1016/01654608[93]90105-U.

[27]. Gedminas J.M., Chasse M.H., McBrairty M., et al. Desmoplastic small round cell tumor is dependent on the EWS-WT1 transcription factor. Oncogenesis. 2020;9:1-8. doi: 10.1038/s41389-020-0224-1.

[28]. Scharnhorst V., van der Eb A.J., Jochemsen A.G et al. WT1 proteins: Functions in growth and differentiation. Gene. 2001;273:141-161. doi: 10.1016/S0378-1119[01]00593-5.

[29]. Lal D.R., Su W.T., Wolden S.L., Loh K.C., Modak S. et al. Results of multimodal treatment for desmoplastic small round cell tumors. J.PediatrSurg. 2005;40:251, 255. doi: 10.1016/j.jpedsurg.2004.09.046.

[30]. Kis B., O'Regan K.N., Agoston A., Javery O., et al. Imaging of desmoplastic small round cell tumour in adults. Br. J. Radiol. 2012;85:187192. doi: $10.1259 / \mathrm{bjr} / 57186741$.

[31]. Hollingsworth R.E., Jansen K. et al. Turning the corner on therapeutic cancer vaccines. NPJ Vaccines. 2019;8:7. doi: 10.1038/s41541-0190103-y.
[32]. Andrea A Hayes-Jordan, Brian A Coakley, Holly L Green et al. Desmoplastic Small Round Cell Tumor Treated with Cytoreductive Surgery and Hyperthermic Intraperitoneal Chemotherapy: Phase 2 Trial, DOI: 10.1245/s10434-018-6333-9 PMCID: PMC5842144.

[33]. Mallone, S.; De Angelis, R.; Van Der Zwan, J.M.; Trama, A.; Siesling, S.; Gatta, G.; Capocaccia, R. Methodological aspects of estimating rare cancer prevalence in Europe: The experience of the RARECARE project. Cancer Epidemiol. 2013, 37, 850-856.

By using the site/services, you are agreeing to our Policies: https:// escipub.com/terms-privacy-policydisclaimer/ 